\title{
Who Benefits from Environmental Identity? Studying Environmental Identity and Mental Wellbeing in Russia
}

\author{
Boris D. Irkhin ${ }^{\mathrm{a}^{*}}$ \\ a National Research University, Higher School of Economics, Moscow, Russia \\ ${ }^{\star}$ Corresponding author. E-mail: irkhinbd@gmail.com
}

Background. Environmental Identity (EID) is a construct that demonstrates the extent to which people perceive themselves as a part of nature, incorporated in it, and defined by it. This concept, despite being relatively new, has proven to be associated with various beneficial traits such as emotional calmness, vigor, reduced stress, increased attentiveness, and positive mental effect (Kals, Schumacher, \& Montada; Pretty et al.; Hartig et al., Raanaas et al.). It is also connected with nature conservation behavior and empathy towards people and nature (Scott \& Willits; Paul, Hartmann, \& Apaolaza-Ibáñez; Tam; Modi \& Patel).

While there have been analyses correlating personality traits with other naturerelated concepts - e.g., environmental engagement, environmental concern, and ecological behavior (Milfont \& Sibley; Wuertz; Markowitz et al.), there is little evidence of which personality traits are connected with Environmental Identity.

Objective. Current research has three objectives: 1) to test the connection between Environmental Identity and Mental Wellbeing on a Russian sample; 2) to discover which personality traits are connected with Environmental Identity; and 3 ) to find out whether or not these personality traits moderate the Environmental Identity - Mental Wellbeing connection. Three hundred and twelve (312) students, of which $79.2 \%$ were females, participated in the study. The majority of participants (90.4\%) were undergraduate students at Russian universities under 20 years old.

Methods. To perform our study, we used the Environmental Identity scale, the Short Big Five, and the Warwick-Edinburgh Mental Wellbeing Scale.

Results. We confirmed the connection between Environmental Identity and Mental Wellbeing on a Russian sample. Openness to Experience was the only significant personality trait predictor of Environmental Identity. Moderation analysis did not reveal any personality traits to be significant moderators between Environmental Identity and Mental Wellbeing.

Conclusion. We concluded that the impact of Environmental Identity on Mental Wellbeing does not depend on specific personality traits, suggesting that it has a universal resource function, and is important for Russian people in general in terms of their mental wellness.

Keywords:

Environ-

mental

Identity

(EID);

mental

wellbeing;

nature;

personality 


\section{Introduction}

This study is devoted to the construct of Environmental Identity, which represents a feeling of connectedness to nature as a part of a universal life force. It is based on several theories: 1) A. Schweitzer's theory of reverence for life as a fundamental principle of morality; 2) the Deep Ecology theory of A. Næss (perceiving the world as a fragile balance of ecosystems); 3) the Biophilia Hypothesis of E. Wilson (the urge to affiliate with other forms of life); 4) S. Schwartz's theory of basic human values; 5) S. Clayton's theory of Environmental Identity; and 6) studies conducted by K.P. Tam on the topic of human empathy with natural objects.

S. Clayton (2003) describes Environmental Identity as a personal sense of connection to the natural environment, based on history, similarity, and feelings of connection. She considers it a self-concept that demonstrates the extent to which people perceive themselves as a part of nature, incorporated into it, and defined by it (Clayton, 2003). EID is one of the multitude of facets of personal identities (along with physical, social, gender, ethnic, and vocational aspects). A sense of Environmental Identity is fundamentally a recognition of one's interdependence with a larger collective, be it social or, in our case, ecological.

Nowadays, studies of wellbeing are gaining ever greater popularity, as people seek a way for humankind to feel happy, relaxed, and healthy. While scientists are discovering more and more connections between wellbeing and certain psychological predictors, our study aimed to investigate the role of nature in our mental health, as well as to discover who benefits more from interaction with natural surroundings, and who would prefer other means of restoration.

There has been a substantial amount of work showing the restorative effects of nature on people's mental health (Maller et al., 2005). It has already been shown that green places play a significant role in soothing human consciousness and relieving stress, even if they are only the view outside your window (Hartig et al., 2003, Raanaas et al., 2012; Pretty et al., 2005; Ulrich, 1984). Other research shows that experience with nature evokes a more intrinsic motivation in the human personality, including making people seek more closeness to other human beings and community, exercise generosity, and care less about gaining fame and wealth (Weinstein, Przybylski, \& Ryan, 2009).

While people who are connected to nature tend to care more about each other, they also become more concerned about preserving and helping nature (Kals, Schumacher, \& Montada, 1999).

There are a number of studies on the predictive role of Environmental Identity, which reveal the connection between positive environmental attitudes (such as studies of environmental concern) and environmental behavior (nature activism, tending to plants and animals) (Scott \& Willits, 1994; Paul, Hartmann, \& Apaolaza-Ibáñez, 2012; Modi \& Patel, 2016). There is also evidence that a high sense of belonging to nature is linked to more pro-environmental and protective behavior, a sense of efficacy, and feeling responsible for nature (Mobley, Vagias, \& DeWard, 2010; Hoot \& Friedman, 2010; Nisbet \& Zelensky, 2011).

It has also been found that having a high Environmental Identity boosts wellbeing in a broad sense: Hinds and Sparks (2009) suggested that a sense of personal 
meaning, obtained from being in the natural environment, is an important aspect of obtaining a sense of Emotional Wellbeing. Regarding the emotional sphere, there are reports that people with salient Environmental Identity are calm, and exhibit increased mindfulness (Howell et al., 2011). There are also studies reporting a link between EID and happiness, life satisfaction, positive emotional affect, vigor (Capaldi et al., 2014), and stress reduction, along with increased attention span (Mayer et al., 2009). Recent studies on Environmental Identity confirm the connection between EID and empathy between people (Clayton, Nartova-Bochaver, \& Irkhin, 2019); these results are in line with the findings of K.P. Tam (2013), P.W. Schultz (2000), and Shelton \& Rogers (1981).

According to the authors of the Warwick-Edinburgh Mental Wellbeing Scale, Mental Wellbeing, often referred to as positive mental health, covers affective and psychological functioning from both the hedonic and eudemonic perspectives (Tennant et al., 2007). The evidence suggests that the positive effects of experience with nature, condensed in Environmental Identity, account for most of the effects of the listed perspectives of Mental Wellbeing. Hence, we were interested in finding out whether EID connects to Mental Wellbeing, which became the first hypothesis of our study.

It is hard to overestimate the significance of nature for Russian culture, in which nature has strong symbolic, and even religious, meaning, and is masterfully appealed to in literature, music, and visual arts (Gurlenova, 1998; Asaf'ev, 2007; Men'shikova, 2015). In some works of classic Russian literature, the authors use nature as the medium for conveying their philosophical insights; nature's role in a narrative is often as important as that of the characters (Krasnosel'skaya, 2008).

Russia is a country with diverse natural environments. Over the course of its history, it experienced an abrupt transition from a very agricultural country to a heavily industrialized one, and is still dealing with the ecological consequences of that today. Those events have had a noticeable impact on the perception of nature, resulting in a mixture of perspectives ranging from the spiritual to the exclusively materialistic (Oldfield, 2017). Due to these differences, it is important to investigate human-nature relationships in Russia, and to determine whether or not nature is important for the Russian people in terms of their Mental Wellbeing.

Hypothesis 1: Environmental Identity is positively connected with Mental Wellbeing.

Earlier in the paper, we noted various studies of nature's effects on wellbeing. However, we discovered that there has been very little research on this connection in Russia. One of the significant papers demonstrates the soothing effect of nature on death acceptance, and attributes growth in the sense of wellbeing in these cases to the beauty of nature (Chistopolskaya et al., 2017). The current study aims to close the gap in Environmental Identity research in Russia.

Our next objective was to find out whether Environmental Identity is connected to specific personality traits. While analyses have been conducted correlating personality traits with other nature-related concepts - e.g., environmental engagement, environmental concern, and ecological behavior (Milfont \& Sibley, 
2012; Wuertz, 2015; Markowitz et al., 2012), these have provided little evidence of which personality traits are connected with Environmental Identity. The above-listed studies revealed that nature-related concepts consistently correlate with Openness to Experience (Markowitz et al., 2012), Agreeableness (Wuertz, 2015), and often with Conscientiousness (Milfont \& Sibley, 2012). In the current research, we planned to investigate whether certain personality traits are also important in connection with Environmental Identity.

Hypothesis 2: Environmental Identity is positively connected with certain personality traits.

It is known that specific personality traits are connected with Mental Wellbeing, e.g., Emotional Stability (reversed Neuroticism) and Extroversion have been identified as the strongest positive predictors of Mental Wellbeing (Gale et al., 2013). In the study of the tripartite model of Mental Wellbeing, Extroversion, and Emotional Stability have been identified as the strongest positive predictors of Subjective Wellbeing, while Agreeableness and Conscientiousness were also significant, but weaker predictors (Joshanloo, 2019).

So far, we have posited the direct connection between Environmental Identity and Mental Wellbeing; however, we are also interested in finding out whether there is an indirect effect. As mentioned above, there is scientific evidence showing the positive effects of the natural environment. However, we cannot state that the effects are beneficial for everyone in equal measure, regardless of their personality. The idea behind our second hypothesis could be worded as follows: "Do all people benefit from nature in the same way?" It is hard to expect a definitive result, given that we have yet to find the correlates of Environmental Identity among personality traits in the current study. Yet, other studies have shown that personality traits are important for understanding similar nature-related concepts (Lee et al., 2015; Di Fabio \& Kenny, 2018; Di Fabio \& Rosen, 2019).

Hypothesis 3: Personality traits moderate the connection between Environmental Identity and Mental Wellbeing.

We planned to investigate the link between Environmental Identity and Mental Wellbeing, and observe whether or not the Big Five personality traits act as moderators in these relationships. Finding the specific personality traits that boost or suppress the connection between EID and Mental Wellbeing could provide useful data for further studies on Environmental Identity, as well as for practical areas such as nature-guided therapy (Burns, 1998).

\section{Methods}

\section{Participants}

Three hundred and twelve (312) students participated in the study; $79.2 \%$ of them were females. The majority of the participants (90.4\%) were undergraduate students at Russian universities and under 20 years old. There were also middle-aged people between 20 and 40 years old (9.3\%), and people between 40 and 60 years old (1\%). Those who did not complete their questionnaires were excluded from the study. 


\section{Procedure}

We used the Environmental Identity Scale, the Short Big Five Personality Test, and the Warwick-Edinburgh Mental Wellbeing Scale.

Social-demographic parameters of age, gender, ethnicity, and residence were combined into a block of short factual questions: "State your gender, ... level of education, ... residence, ... ethnic group." We also included several questions to evaluate the participants' nature experience: how frequently they walk in the park, travel to the countryside, or donate to the environmental organizations.

To measure the relationship to nature, we chose the Environment Identity (EID) scale. This scale was developed by Susan Clayton (Clayton, 2003; Clayton, Nartova-Bochaver, \& Irkhin, 2019). It utilizes the concept of natural identity, defining it as a way in which people form their self-concept based on a sense of connection to a non-human environment, which means they consider nature to be an important part of themselves and vice versa. The scale consists of 24 statements, each of which represents a different aspect of the relationship between humans and nature. Each respondent was asked to think carefully about each of the statements, visualize them, and answer how well the statement reflects their position regarding their lifestyle (Strongly disagree, disagree, agree, or strongly agree). The EID is a well-known scale with a high level of reliability which has been tested in previous research (Olivos, \& Aragones, 2011).

Mental Wellbeing was measured by the Warwick-Edinburgh Mental Wellbeing Scale (WEMWBS). It was developed to facilitate the monitoring of Mental Wellbeing among the general population, and to evaluate projects, programs, and policies which aim to improve Mental Wellbeing (Tennant et al., 2007; NartovaBochaver, Podlipnyak \& Khokhlova, 2013). The WEMWBS is a 14-item scale with five response categories; added together, they comprise a single score which ranges from 14 to 70 . All the items are worded positively and cover both the emotional and functional aspects of Mental Wellbeing, thereby making the concept more accessible. The scale has been widely used nationally and internationally for monitoring and evaluating projects and programs, and investigating the determinants of Mental Wellbeing.

To measure personality traits, we chose the Short Big Five questionnaire, which is used worldwide as a tool for measuring the five most important personality dimensions; these are Openness, Conscientiousness, Extraversion, Agreeableness, and Neuroticism (the opposite of the Emotional Stability) (Lang et al., 2011). The scale consists of 14 items which describe people's typical mental states (e.g., "I feel empowered," "I am interested in something new," "I am relaxed"). The answers are assessed on a 5-point Likert scale, which registers how often those states occur (from "never" to "usually"). We chose the short version in order to shorten the time needed for completion of the survey.

The questionnaire was created and distributed online via the 1.ka online platform. The analyses were conducted via IBM SPSS Statistics 26 software and a PROCESS (ver. 3.5) plug-in for moderation analysis (Hayes, 2012). 


\section{Results}

The sample is described in Table 1.

Table 1

Descriptive characteristics of the participants

\begin{tabular}{llccc}
\hline \multicolumn{1}{c}{ Variable } & \multicolumn{1}{c}{ Categories } & N & Percent & $\begin{array}{c}\text { Cumulative } \\
\text { percentage }\end{array}$ \\
\hline \multirow{2}{*}{ Gender } & Male & 65 & 20.8 & 20.8 \\
& Female & 247 & 79.2 & 100 \\
Age & $<20$ & 282 & 90.4 & 90.4 \\
& $21-40$ & 29 & 9.3 & 99.7 \\
& $41-60$ & 1 & .3 & 100 \\
Ethnicity & Russian & 273 & 87.5 & 87.5 \\
& Caucasian & 10 & 3.2 & 90.7 \\
& Central Asian & 5 & 1.6 & 92.3 \\
& Other & 19 & 6.1 & 98.4 \\
& Not specified & 5 & 1.6 & 100 \\
Residence & City & 259 & 83 & 83 \\
& Suburbs & 43 & 13.8 & 96.8 \\
& $<1$ hour away & 8 & 2.6 & 99.4 \\
& from the closest city & & & 100 \\
& $>1$ hour away & 2 & .6 & \\
& from the closest city & & & \\
\hline
\end{tabular}

Note. $N=312$

First of all, we checked whether there was a positive connection between Environmental Identity and Mental Wellbeing. There was a significant correlation between the EID and WEMWBS scales $(\mathrm{rs}=.23, \mathrm{p}<.01)$, telling us that relatedness to nature is connected with Mental Wellbeing, as we hypothesized.

Table 2

Correlations between Big Five traits and EID, WEMWBS scales (Spearman's rho)

\begin{tabular}{lccccc}
\hline \multicolumn{1}{c}{ Variable } & Extraversion & Agreeableness & $\begin{array}{c}\text { Conscien- } \\
\text { tiousness }\end{array}$ & Stability & Openness \\
\hline $\begin{array}{l}\text { Environmental } \\
\text { Identity }\end{array}$ & .11 & $.13^{*}$ & .07 & -.01 & $.26^{\star *}$ \\
$\begin{array}{l}\text { Mental Wellbe- } \\
\text { ing }\end{array}$ & $.36^{\star *}$ & $.14^{\star}$ & $.29^{* *}$ & $.39^{* *}$ & $.21^{\star *}$ \\
\hline
\end{tabular}

Note. ${ }^{\star}$ Significant at $p<.05 ;{ }^{*}$ Significant at $p<.01$ 
In describing their Big Five personality traits, the respondents showed high levels of Openness $(M=5.22, S D=1.01)$, Conscientiousness $(M=4.95, S D=1.34)$ and Agreeableness $(M=4.28, S D=.98)$, with average scores on Extraversion $(M=3.92$, $\mathrm{SD}=1.47)$ and Emotional Stability (reversed Neuroticism) $(\mathrm{M}=3.52, \mathrm{SD}=1.44)$. We then added the Big Five traits into a correlation analysis, the results of which are displayed in the Table 2.

Statistical analysis revealed significant positive correlations between the degrees of EID and the Big Five traits of Agreeableness and Openness to Experience, partially supporting our second hypothesis. The Agreeableness correlation was less significant $(\mathrm{p}<.05)$ than Openness to Experience $(\mathrm{p}<.01)$. All Big Five traits were correlated with Mental Wellbeing. These results are in line with the bulk of the studies, which were thoroughly described in the meta-synthesis study on personality predicting overall health and Mental Wellbeing by Strickhouser, Zell, \& Krizan (2017).

In order to find the significant predictors among the Big Five traits and Environmental Identity, we conducted a multiple regression analysis. A significant equation was found $(\mathrm{F}(1,314)=19.106, p<.000)$, with an $\mathrm{R}^{2}$ of .06 . The participants' predicted Environmental Identity was equal to $2.237+.163$ (Openness). Environmental Identity increased .16 points for each point of Openness score. Openness was the only significant predictor of Environmental Identity.

We then proceeded to moderation analysis. In order to meet the required assumptions, we checked the data for outliers and removed them; there were four such cases. The outcome variable for the analysis was Mental Wellbeing, and the predictor variable was Environmental Identity. We have processed each of the Big Five traits as moderator variables. However, the interactions between Openness $[\mathrm{B}=.03,95 \%$ C.I. $(-.07, .12), p=.59]$, Conscientiousness $[\mathrm{B}=.02,95 \%$ C.I. $(-.04, .09), p=.47]$, Extraversion $[\mathrm{B}=-.04,95 \%$ C.I. $(-.11, .02), p=.20]$, Agreeableness $[\mathrm{B}=.04,95 \%$ C.I. $(-.03, .12), p=.26]$ and Emotional Stability $[\mathrm{B}=-.01,95 \%$ C.I. $(-.06, .04), p=.58]$ were not found to be statistically significant. The results of the moderation analysis with Openness alone as a moderator variable are displayed in Figure 1.

We also conducted a correlational analysis and compared mean scores between several items on the social-demographic block of questions (Table 3):

Table 3

Correlations between EID, WEMWBS, and social-demographic data (Spearman's rho)

\begin{tabular}{lccccc}
\hline \multicolumn{1}{c}{ Variable } & Age & Residence & $\begin{array}{c}\text { Park walks/ } \\
\text { week }\end{array}$ & $\begin{array}{c}\text { Countryside } \\
\text { trips/week }\end{array}$ & $\begin{array}{c}\text { Env. organizations } \\
\text { membership }\end{array}$ \\
\hline Environmental Identity & -.078 & .04 & $.25^{* *}$ & $.29^{* *}$ & $.23^{* *}$ \\
Mental Wellbeing & .03 & -.06 & $.21^{* *}$ & $.22^{* *}$ & .04 \\
\hline
\end{tabular}

Note. ${ }^{* \star S i g n i f i c a n t ~ a t ~} p<.01$

Age and residence were unrelated to Environmental Identity and Mental Wellbeing, while the number of park walks and countryside trips per week were con- 


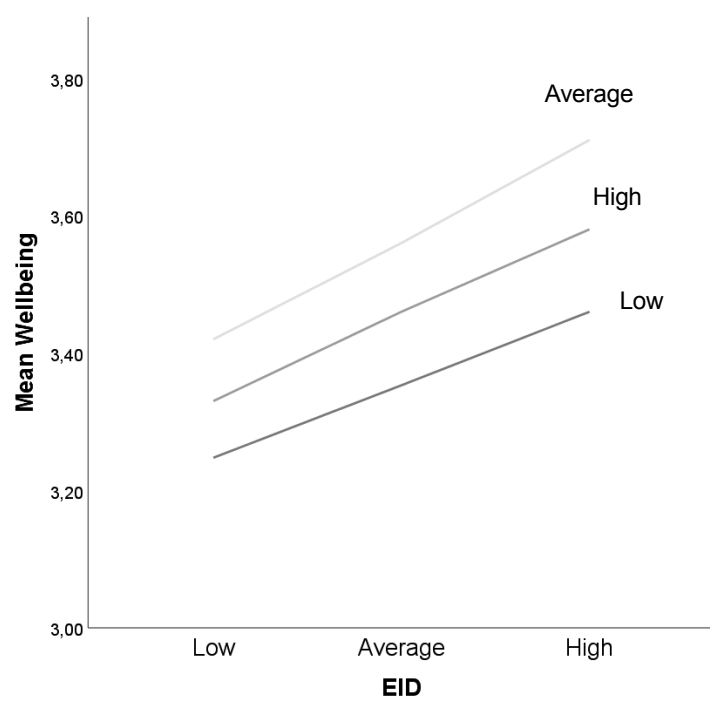

Figure 1. Moderation analysis results with Openness

nected with both EID and WEMWBS. The number of environmental organizational memberships positively correlated only with EID, but not WEMWBS.

We conducted a single samples t-test to compare Environmental Identity scores for the male and female respondents. There was a significant difference between EID scores for male $(M=2.89, S D=.64)$ and female respondents $(M=3.16$, $\mathrm{SD}=.71) ; \mathrm{t}(310)=-2.83, \mathrm{p}=.005$. On the contrary, there were no significant differences in Mental Wellbeing scores between the sexes.

ANOVA results showed no significant differences in either Environmental Identity or Mental Wellbeing among ethnic groups; however, the groups were very unevenly represented in our sample (See Table 1).

\section{Discussion}

As we expected, we confirmed a link between Environmental Identity and Mental Wellbeing, which can mean several things. For example: Urban life, which attracts an increasing number of people, often deprives them of interaction with nature, creating a so-called "nature deficit disorder" (Louv, 2008), and raising their need for it. Nature is often valued as a source of beauty and inspiration (Capaldi et al., 2017); it helps a person to restore attentiveness (Kaplan, 1993) and to recover from stress (Ulrich et al., 1991). Nature is also a valuable resource, which is even demonstrated by the housing market; people tend to pay a higher price for the dwellings with a view of natural landscapes (Jim \& Chen, 2009; Cavailhès et al., 2009; Wen, Xiao, \& Zhang, 2017).

Our findings suggest that Environmental Identity is important for Russian people in terms of their mental wellness and is in line with similar findings in other countries (Elings, 2006; Hinds \& Sparks, 2011; Capaldi et al., 2015; Capaldi et al., 2017). Moreover, the positive connection between Mental Wellbeing, Environmental Identity, and experience with nature (walks in the parks, trips to the country- 
side) indirectly supports the idea of the negative effect of urbanization in a narrow sense, and signifies the importance of green areas in megapolises (Hartig et al., 2003, Raanaas et al., 2012; Pretty et al., 2005; Ulrich, 1984).

Our second hypothesis was that Environmental Identity is connected with certain personality traits. We have found that EID correlates significantly with Openness to Experience and Agreeableness traits; however, the correlations were weak. Regression analysis confirmed that Openness was the only significant predictor of Environmental Identity. As we discussed, similar nature-related constructs (environmental concern, connectedness to nature, dispositional empathy with nature) often correlate with Openness to Experience, Agreeableness, and Conscientiousness (Milfont \& Sibley, 2012; Tam, 2013; Abdollahi et al., 2017; Strickhouser, Zell, \& Krizan, 2017; Di Fabio \& Kenny, 2018). The current study provides the first evidence of the relationship between the Big Five personality traits and EID; this follows the tendency of other natural constructs, but needs additional confirmation by other studies.

The results of the moderation analyses were insignificant, which tells us that personality traits have not influenced the connection between Environmental Identity and Mental Wellbeing.

\section{Conclusion}

The main goals of the current study were to test the link between Environmental Identity and Mental Wellbeing on a Russian sample, and investigate the role of personality traits in relation to Environmental Identity, and its benefits for Mental Wellbeing. We have successfully confirmed the connection between Environmental Identity and Mental Wellbeing on a Russian sample. Russian people are known for being close to nature from their cultural heritage: the admiration of nature is found in famous works of art by I. Aivazovsky, K. Korovin, A Kuindzhi, and many others, including many world-famous Russian writers and poets, who have incorporated very emotional and symbolic images of nature into their masterpieces. Our findings suggest that Environmental Identity is important for Russian people in terms of their mental wellness, and are in line with similar findings in other countries (Elings, 2006; Hinds \& Sparks, 2011; Capaldi et al., 2015; Capaldi et al., 2017).

While other nature-related constructs have been found to be connected to personality traits, no evidence of Environmental Identity had been found to have that link. Our study closes this gap: we have discovered that Environmental Identity is connected to Openness and Agreeableness personality traits, with Openness being the only significant predictor of EID.

Overall, we have not confirmed our hypothesis regarding the role of certain personality traits as a resource function for Environmental Identity: none of the interactions between Big Five traits and EID were statistically significant. This could mean that humans benefit from being close to nature and identify themselves with it regardless of their personality. On the other hand, our findings are limited by our sample, which appears to have been very homogeneous. So far, it is hard to give a straight answer as to whether personality traits influence the relationship between Environmental Identity and Mental Wellbeing. Perhaps a more varied sample, with more diverse personality profiles, could help to address this specifically. 


\section{Limitations}

The majority of our sample were Russian undergraduate students, which substantially limits the explanatory power of the study. While the short Big Five inventory allowed us to reduce the survey item count, it could have made the sample too homogeneous to find distinct moderators among personality traits. Perhaps we should use the original 44 -item inventory in the future to get more diverse results.

Future research should also include people from a wider age range, with different experiences of nature, including both metropolis and countryside dwellers, active explorers of nature (tourists, survivalists, farmers), and people who are less enthusiastic about nature. It is also important to utilize different methods of measurement (e.g., the Temperament and Character Inventory by R. Cloninger, the 16PF Questionnaire by R. Cattel, etc.) for profiling. With these improvements, we hope to find even more fascinating nuances of the human-nature relationship, and perhaps an easier way for people to find happiness in nature.

\section{Acknowledgements}

This study was funded by the RFBR, project number 19-013-00216.

\section{References}

Abdollahi, A., Hosseinian, S., Karbalaei, S., Beh-Pajooh, A., Keshavarz, Y., \& Najafi, M. (2017). The Big Five personality traits and environmental concern: the moderating roles of individualism/ collectivism and gender. Romanian Journal of Psychology, 19(1).

Asaf'ev, B. (2007). O russkoj prirode i russkoj muzyke [Russian nature and Russian music]. Iskusstvo $v$ shkole [Art at school], 1, 7-11.

Burns, G.W. (1998). Nature-guided therapy: Brief integrative strategies for health and well-being. Psychology Press.

Capaldi, C., Dopko, R.L., \& Zelenski, J.M. (2014). The relationship between nature connectedness and happiness:ameta-analysis.FrontiersinPsychology,5,976.https://doi.org/10.3389/fpsyg.2014.00976

Capaldi, C.A., Passmore, H.A., Ishii, R., Chistopolskaya, K.A., Vowinckel, J., Nikolaev, E.L., \& Semikin, G.I. (2017). Engaging with natural beauty may be related to well-being because it connects people to nature: Evidence from three cultures. Ecopsychology, 9(4), 199-211. https://doi.org/10.1089/eco.2017.0008

Capaldi, C.A., Passmore, H.A., Nisbet, E.K., Zelenski, J.M., \& Dopko, R.L. (2015). Flourishing in nature: A review of the benefits of connecting with nature and its application as a wellbeing intervention. International Journal of Wellbeing, 5(4). https://doi.org/10.5502/ijw.v5i4.449

Cavailhès, J., Brossard, T., Foltête, J.C., Hilal, M., Joly, D., Tourneux, F.P., ... Wavresky, P. (2009). GIS-based hedonic pricing of landscape. Environmental and Resource Economics, 44(4), 571-590. https://doi.org/10.1007/s10640-009-9302-8

Clayton, S.D. (2003). Identity and the natural environment: The psychological significance of nature. MIT Press. https://doi.org/10.7551/mitpress/3644.001.0001

Clayton, S., Irkhin, B., \& Nartova-Bochaver, S. (2019). Environmental identity in Russia: Validation and relationship to the concern for people and plants. Psychol. J. High. Sch. Econ, 16, 85-107. https://doi.org/10.17323/1813-8918-2019-1-85-107

Diener, E., Lucas, R.E., \& Oishi, S. (2002). Subjective well-being: The science of happiness and life satisfaction. Handbook of Positive Psychology, 2, 63-73.

Di Fabio, A., \& Kenny, M.E. (2018). Connectedness to nature, personality traits and empathy from a sustainability perspective. Current Psychology, 1-12. https://doi.org/10.1007/s12144-018-0031-4 
Di Fabio, A., \& Rosen, M.A. (2019). Accounting for individual differences in connectedness to nature: Personality and gender differences. Sustainability, 11(6), 1693.https://doi.org/10.3390/su11061693

Elings, M. (2006). People-plant interaction: the physiological, psychological and sociological effects of plants on people. In Farming for Health (pp. 43-55). Springer, Dordrecht. https://doi.org/10.1007/1-4020-4541-7_4

Engemann, K., Pedersen, C.B., Arge, L., Tsirogiannis, C., Mortensen, P.B., \& Svenning, J.C. (2019). Residential green space in childhood is associated with lower risk of psychiatric disorders from adolescence into adulthood. Proceedings of the National Academy of Sciences, 116(11), 51885193. https://doi.org/10.1073/pnas.1807504116

Gale, C.R., Booth, T., Mõttus, R., Kuh, D., \& Deary, I.J. (2013). Neuroticism and Extraversion in youth predict mental wellbeing and life satisfaction 40 years later. Journal of Research in Personality, 47(6), 687-697. https://doi.org/10.1016/j.jrp.2013.06.005

Gurlenova, L.V. (1998). Chuvstvo prirody v russkoj proze 1920-1930-h gg [A sense of nature in Russian prose of the 1920-1930s.]. Syktyvkarskii un-t [Syktyvkar State University].

Hartig, T., Evans, G.W., Jamner, L.D., Davis, D.S., \& Gärling, T. (2003). Tracking restoration in natural and urban field settings. Journal of Environmental Psychology, 23(2), 109-123. https://doi.org/10.1016/S0272-4944(02)00109-3

Hartmann, P., \& Apaolaza-Ibáñez, V. (2012). Consumer attitude and purchase intention toward green energy brands: The roles of psychological benefits and environmental concern. Journal of Business Research, 65(9), 1254-1263. https://doi.org/10.1016/j.jbusres.2011.11.001

Hayes, A.F. (2012). PROCESS: A versatile computational tool for observed variable mediation, moderation, and conditional process modeling. Retrieved from https://afhayes.com/public/process2012.pdf

Hinds, J., \& Sparks, P. (2009). Investigating environmental identity, well-being, and meaning. Ecopsychology, 1(4), 181-186. https://doi.org/10.1089/eco.2009.0026

Hoot, R.E., \& Friedman, H. (2010). Connectedness and environmental behavior: Sense of interconnectedness and pro-environmental behavior. Transpersonal Studies, 30(1-2), 89-100.

Howell, A.J., Dopko, R.L., Passmore, H.A., \& Buro, K. (2011). Nature connectedness: Associations with well-being and mindfulness. Personality and Individual Differences, 51(2), 166-171. https://doi.org/10.1016/j.paid.2011.03.037

Jim, C.Y., \& Chen, W.Y. (2009). Value of scenic views: Hedonic assessment of private housing in Hong Kong. Landscape and Urban Planning, 91(4), 226-234. https://doi.org/10.1016/j.landurbplan.2009.01.009

Joshanloo, M. (2019). Structural and discriminant validity of the tripartite model of mental wellbeing: differential relationships with the big five traits. Journal of Mental Health, 28(2), 168-174. https://doi.org/10.1080/09638237.2017.1370633

Kaplan, R. (1973). Some psychological benefits of gardening. Environment and Behavior, 5(2), 145-162. https://doi.org/10.1177/001391657300500202

Kaplan, R. (1993). The role of nature in the context of the workplace. Landscape and Urban Planning, 26(1-4), 193-201. https://doi.org/10.1016/0169-2046(93)90016-7

Kals, E., Schumacher, D., \& Montada, L. (1999). Emotional affinity toward nature as a motivational basis to protect nature. Environment and Behavior, 31(2), 178-202. https://doi.org/10.1177/00139169921972056

Krasnosel'skaya, Yu.I. (2008). Simvolika prirody v tvorchestve LN Tolstogo 1850-60-h gg. v kontekste literaturnyh i obshchestvenno-politicheskih polemik epohi [The symbolism of nature in the works of Tolstoy in the 1850-60s in the context of literary and socio-political polemics of the era]. (Doctoral dissertation).

Lang, F.R., John, D., Ludtke, O., Schupp, J., \& Wagner, G.G. (2011). Short assessment of the Big Five: robust across survey methods except telephone interviewing. Behavior Research Methods, 43, 548-567. https://doi.org/10.3758/s13428-011-0066-Z

Lee, K., Ashton, M.C., Choi, J., \& Zachariassen, K. (2015). Connectedness to nature and to humanity: Their association and personality correlates. Frontiers in Psychology, 6, 1003. https://doi.org/10.3389/fpsyg.2015.01003 
Louv, R. (2008). Last child in the woods: Saving our children from nature-deficit disorder. NY: Algonquin books.

Markowitz, E.M., Goldberg, L.R., Ashton, M.C., \& Lee, K. (2012). Profiling the "pro-environmental individual": A personality perspective. Journal of Personality, 80(1), 81-111. https://doi.org/10.1111/j.1467-6494.2011.00721.x

Milfont, T.L., \& Sibley, C.G. (2012). The big five personality traits and environmental engagement: Associations at the individual and societal level. Journal of Environmental Psychology, 32(2), 187-195. https://doi.org/10.1016/j.jenvp.2011.12.006

Men'shikova, A.A. (2015). Tradicii pejzazhnoj liriki v russkoj zhivopisi XIX-nachala XX veka [Traditions of landscape lyrics in Russian painting of the 19th - early 20th centuries]. Filologicheskie nauki. Voprosy teorii i praktiki [Philological sciences. Questions of theory and practice], (8-2), $120-126$.

Mobley, C., Vagias, W.M., \& DeWard, S.L. (2010). Exploring additional determinants of environmentally responsible behavior: The influence of environmental literature and environmental attitudes. Environment and Behavior, 42(4), 420-447. https://doi.org/10.1177/0013916508325002

Nartova-Bochaver, S.K., Podlipnyak, M.B., \& Khokhlova, A.Y. (2013). Vera v spravedlivyi mir i psikhologicheskoe blagopoluchie u glukhikh i slyshashchikh podrostkov i vzroslykh [Belief in a Just World and Psychological Well-Being in Deaf and Hearing Adolescents and Adults]. Klinicheskaya i spetsialnaya psikhologiya [Clinical and Special Psychology], 2(3).

Naess, A. (1987). Self-realization: An ecological approach to being in the world. The Trumpeter, 4(3).

Nisbet, E.K., Zelenski, J.M., \& Murphy, S.A. (2011). Happiness is in our nature: Exploring nature relatedness as a contributor to subjective well-being. Journal of Happiness Studies, 12(2), 303-322. https://doi.org/10.1007/s10902-010-9197-7

Oldfield, J.D. (2017). Russian nature: exploring the environmental consequences of societal change. Routledge. https://doi.org/10.4324/9781315243863

Olivos, P., \& Aragonés, J.I. (2011). Propiedades psicométricas de la Escala de Identidad Ambiental (EID) [Psychometric properties of the Environmental Identity Scale (EID)]. Psyecology, 2(1), 15-24. https://doi.org/10.1174/217119711794394671

Paul, J., Modi, A., \& Patel, J. (2016). Predicting green product consumption using theory of planned behavior and reasoned action. Journal of Retailing and Consumer Services, 29, 123-134. https://doi.org/10.1016/j.jretconser.2015.11.006

Pretty, J., Peacock, J., Sellens, M., \& Griffin, M. (2005). The mental and physical health outcomes of green exercise. International Journal of Environmental Health Research, 15(5), 319-337. https://doi.org/10.1080/09603120500155963

Raanaas, R.K., Patil, G.G., \& Hartig, T. (2012). Health benefits of a view of nature through the window: a quasi-experimental study of patients in a residential rehabilitation center. Clinical Rehabilitation, 26(1), 21-32. https://doi.org/10.1177/0269215511412800

Schultz, P. (2000). New Environmental Theories: Empathizing With Nature: The Effects of Perspective Taking on Concern for Environmental Issues. Journal of Social Issues, 56(3), 391-406. https://doi.org/10.1111/0022-4537.00174

Scott, D., \& Willits, F.K. (1994). Environmental attitudes and behavior: A Pennsylvania survey. Environment and Behavior, 26(2), 239-260. https://doi.org/10.1177/001391659402600206

Shelton, M.L., \& Rogers, R.W. (1981). Fear-arousing and empathy-arousing appeals to help: The pathos of persuasion. Journal of Applied Social Psychology, 11(4), 366-378. https://doi.org/10.1111/j.1559-1816.1981.tb00829.x

Strickhouser, J.E., Zell, E., \& Krizan, Z. (2017). Does personality predict health and well-being? A metasynthesis. Health Psychology, 36(8), 797. https://doi.org/10.1037/hea0000475

Tam, K.P. (2013). Dispositional empathy with nature. Journal of Environmental Psychology, 35, 92 104. https://doi.org/10.1016/j.jenvp.2013.05.004

Tennant, R., Hiller, L., Fishwick, R., Platt, S., Joseph, S., Weich, S., ... Stewart-Brown, S. (2007). The Warwick-Edinburgh mental well-being scale (WEMWBS): development and UK validation. Health and Quality of Life Outcomes, 5(1), 63. https://doi.org/10.1186/1477-7525-5-63 
Ulrich, R.S. (1984). View through a window may influence recovery from surgery. Science, 224(4647), 420-421. https://doi.org/10.1126/science.6143402

Ulrich, R.S., Simons, R.F., Losito, B.D., Fiorito, E., Miles, M.A., \& Zelson, M. (1991). Stress recovery during exposure to natural and urban environments. Journal of Environmental Psychology, 11(3), 201-230. https://doi.org/10.1016/S0272-4944(05)80184-7

Wen, H., Xiao, Y., \& Zhang, L. (2017). Spatial effect of river landscape on housing price: An empirical study on the Grand Canal in Hangzhou, China. Habitat International, 63, 34-44. https://doi.org/10.1016/j.habitatint.2017.03.007

Wuertz, T. R. (2015). Personality traits associated with environmental concern (Doctoral dissertation). Walden University. Retrieved from https://scholarworks.waldenu.edu/dissertations/308

Original manuscript received January 10, 2019

Revised manuscript accepted July 29, 2020

First published online September 15, 2020

To cite this article: Irkhin, B.D. (2020). Who Benefits from Environmental Identity? Studying Environmental Identity and Mental Wellbeing in Russia. Psychology in Russia: State of the Art, 13(3), 66-78. DOI: 10.11621/pir.2020.0305 